$\Phi=$

\title{
Trends of fire deaths and effects of fire safety measures in Taiwan during 1971-2015
}

\author{
Yen-Hsiung Liao * \\ Department of Health Sciences, School of Public Health, Kaohsiung Medical University, Kaohsiung, Taiwan \\ *Corresponding author E-mail: bany0309@yahoo.com.tw
}

\begin{abstract}
Purpose: Although fire causes $2 \%$ of deaths of the global accidents in Taiwan, injury or death caused by fire is frequent and largely preventable.

Approach: Using the Health and Vital Statistics, Fire Losses and Casualties Table, Abridged Life Tables, and Services for Fire Fighting by official publications during 1971-2015, we approached the trends of population, ages, gender, and social costs associated with fatal fire and evaluated the effects of fire safety measures.

Results: The higher mortality rate of fire death was in the elders. Fire death rates were 1.92 folds higher risk in males than in females (p $<0.05$ ). The potential years of life lost (PYLL) implied the most efficient evaluation for the fire safety measures. Fire mortality and casualty could be prevented by fire prevention, fire rescue and emergency medical measures effectively. The most significant effect of fire safety measures was evasion training that adopted the indicator of mortality per 102 burned houses (MBH).

Conclusions: Therefore, fire prevention efforts should concentrate on males, and elders. The decreasing of fire numbers should be developed and encouraged.
\end{abstract}

Keywords: Fire; Potential Years of Life Lost; Evasion Training.

\section{Introduction}

On average, there were 220 people died, 442 people injured, and 148 burned houses per year in Taiwan from 1971 to 2015 (Ministry of Health and welfare, 1971-2015b). Although fire caused $2 \%$ of deaths of the global accidents, fire made health, social, and environmental damage immensely. Therefore, the National Fire Agency set up in 1995, which adopted in fire prevention, rescue, and emergency medical services, and expanded organizations to cope with the disasters in 2001(National Fir Agency, Ministry of Interior, 2015).

Injury or death caused by fire is frequent and largely preventable (Barillo \& Goode 1996). The growing emphasis on fiscal responsibility, annual estimates of injury costs can be as meaningful and relevant to safety and health measures as data on injury incidence and severity (Etter,1987). This study attempts to define the trends of population, ages, gender, locations, and social costs associated with fatal fire, and furthermore determine the changing of fire deaths after the intensification of fire mitigation during 1971-2015. The results would help to assess the future needs of support services for the fire fighting and public health units to meet the demands of fire safety.

\section{Methods}

Using Health and Vital Statistics, Fire Losses and Casualties Table, Abridged Life Tables, and Services for Fire Fighting by official publications during 1971-2015, (Ministry of Health and Welfare, 1971-2015b; Ministry of Interior, 2015), we computed the life expectancy due to elimination of death caused by fire and flames
(ICD-9, E890-E899; ICD-10, X00-X09). The results were computed for the race- gender specific population in Taiwan.

There are three ways of weighting the number of deaths due to fire cause in the study. The form for the crude death rates (CDR) is $\mathrm{CDR}=\sum_{i=0}^{\infty} d i / \sum_{i=0}^{\infty} n i$, where di is the number of deaths from the cause under concern in the ith age group, and ni is the number of persons under concern in the ith age group (Miettinen 1972). The form for potential years of life lost (PYLL) is PYLL $=\Sigma(70-$ age at the time of death). The form for average years of life lost (AYLL) is AYLL $=$ PYLL / number of death.

Three indicators are adopted for explaining the safety measures, such as proportion of smoking cause (PSC), mortality per $10^{2}$ burned houses $(\mathrm{MBH})$, and fire casualty rate (FCR). PSC and $\mathrm{MBH}$ are the indicators of fire prevention effects; PSC is meant to fire safety education, and MBH is meant to evasion training.FCR is as the indicator of fire rescue and as the indicator of emergency medical services effects.

In order to confirm the efforts of fire safety measures, another four of fire services and call frequency initiatives are adopted for the analysis of impacts on mortality and casualty during 1995-2015. Rates of unqualified recheck (RUR) was as the initiatives of fire prevention. Persons attendance at every fire accident (PAF), engines attendance at every fire accident (EAF), and number of saving per fire (SAV), are as the rescue, and emergency medical services.

Differences between various groups were evaluated using Student's t-test and $\mathrm{x}^{2}$-test. The level of significance was set at 0.05 . 


\section{Results}

\subsection{Incidence}

During 1971-2015 the total number of fires, and burned houses, and casualty were increased from 2649,1943 , and 344 to 1704 1477 , and 365 . The number of fires (28254), and burned houses (3384) were both peak in 1999 and declined to the lowest after 2000. The number of casualty (1195) was peak in 1993 and declined to the lowest after 1995 .

\subsection{Mortality}

The mortalities during 1971-2015 by nine year interval are seen in table 1 . The average CDR is 1.10 per $10^{5}$ persons. Males appear to be about 2 folds greater risk than females for those during $15-64$ years age group, and over 64 years age group. The average CDRs of males, females, and both sexes are $3.95,2.03$, and 3.01 per $10^{5}$ persons over 64 years age group, which are about 3.76 folds, 2.11 folds, and 2.98 folds greater risk than the average CDRs of males, females, and both sexes under15 years age group (all $\mathrm{p}<0.05$ ). Likely they are about 3.21 folds, 2.94 folds, and 3.24 folds greater risk than the average CDRs of males, females, and both sexes in 15-64 years age group in male, female, and both sexes (all p<0.05) The average CDRs of males, females, and both sexes are 2.29, 1.85 , and 1.85 per $10^{5}$ persons during $1989-1997$ which declined to $0.61,0.33$, and 0.46 per $10^{5}$ persons during $2007-2015$ (26.64 \%, $17.83 \%$, and $24.86 \%$; $<0.05$ ). The average CDRs of males, females, and both sexes are $1.70,1.44$, and 1.58 per $10^{5}$ persons under 15 years age group during 1989-1997 which declined to $0.33,0.27$, and 0.30 per $10^{5}$ persons during $2007-2015(19.41 \%$, $18.75 \%$, and $18.99 \%$; $<$ < 0.05). The average CDRs of males, females, and both sexes are $2.21,1.46$, and 1.72 per $10^{5}$ persons in 15-64 years age group during 1989-1997 which declined to 0.47 , 0.25 , and 0.34 per $10^{5}$ persons during 2007-2015 $(21.27 \%, 17.12$ $\%$, and $19.77 \%$; $<<0.05$ ). The average CDRs of males, females, and both sexes are 5.12, 2.85, and 4.08 per $10^{5}$ persons over 65 years age group during 1989-1997 which declined to 1.92, 0.88, and 1.41 per $10^{5}$ persons during $2007-2015(37.50 \%, 30.88 \%$, and $34.56 \%$; $<0.05)$. The declined rates were larger in females than in males. The declined rates were smaller in over 64 years age group than in under 15 years age group, and in $15-64$ years age group respectively.

\subsection{Potential years of life lost (PYLL), and average years of life lost (AYLL)}

Social costs caused by fire death are displayed in table 2. Comparing these totals by sex, we see that there are greater losses in potential life years among men than women with fire deaths. All of them were with an average loss of 42 years by affected individuals The PYLL of males, females, and both sexes were 10216, 7103, and 17455 person years during 1989-1997, which declined to 2038, 586, and 2623 person years during 2007-2015 (19.95\%, $8.25 \%$, and $15.03 \%$; $<0.05$ ). The AYLL of male, female, and both sexes were 41,51 , and 45 person years during 1989-1997, which declined to 29,28 , and 29 person years during 2007-2015 $(70.73 \%, 54.90 \%$, and $64.44 \% ; \mathrm{p}<0.05)$.

Table 1: Ages and Sex Distribution of Fire Mortality per $10^{5}$ Persons (1971-2015)

\begin{tabular}{|c|c|c|c|c|c|c|c|c|c|c|c|c|}
\hline Year & Male & $\begin{array}{l}<15 \text { years } \\
\text { Female }\end{array}$ & Both & Male & $\begin{array}{l}15- \\
64 y e a r s \\
\text { Female }\end{array}$ & Both & Male & $\begin{array}{l}>64 \text { years } \\
\text { Female }\end{array}$ & Both & Male & $\begin{array}{l}\text { Total } \\
\text { Female }\end{array}$ & Both \\
\hline $\begin{array}{l}1971- \\
1979\end{array}$ & 1.04 & 0.88 & 0.96 & 0.99 & 0.44 & 0.69 & 3.93 & 3.17 & 3.01 & 1.10 & 0.66 & 0.88 \\
\hline $\begin{array}{l}1980- \\
1988\end{array}$ & 1.37 & 1.41 & 1.39 & 1.63 & 0.85 & 1.22 & 6.02 & 2.78 & 4.44 & 1.76 & 1.43 & 1.43 \\
\hline $\begin{array}{l}1989- \\
1997\end{array}$ & 1.70 & 1.44 & 1.58 & 2.21 & 1.46 & 1.72 & 5.12 & 2.85 & 4.08 & 2.29 & 1.85 & 1.85 \\
\hline $\begin{array}{l}1998- \\
2006\end{array}$ & 0.80 & 0.81 & 0.81 & 0.87 & 0.51 & 0.66 & 2.75 & 1.46 & 2.11 & 1.03 & 0.65 & 0.90 \\
\hline $\begin{array}{l}2007- \\
2015\end{array}$ & 0.33 & 0.27 & 0.30 & 0.47 & 0.25 & 0.34 & 1.92 & 0.88 & 1.41 & 0.61 & 0.33 & 0.46 \\
\hline Total & 0.33 & 0.27 & 0.30 & 0.47 & 0.25 & 0.34 & 1.92 & 0.88 & 1.41 & 0.61 & 0.33 & 0.46 \\
\hline
\end{tabular}

Table 2: Estimated Number of Lost Life Years Associated with the Incidence of Fire, Taiwan, 1971-2015

\begin{tabular}{|c|c|c|c|c|c|c|}
\hline Year & $\begin{array}{l}\text { PYLL } \\
\text { Male }\end{array}$ & $\begin{array}{l}\text { (person years) } \\
\text { Female }\end{array}$ & Both & $\begin{array}{l}\text { AYLL } \\
\text { Male }\end{array}$ & $\begin{array}{l}\text { (years) } \\
\text { Female }\end{array}$ & Both \\
\hline 1971-1979 & 4367 & 2929 & 7169 & 47 & 59 & 50 \\
\hline $1980-1988$ & 7245 & 5415 & 12682 & 43 & 56 & 47 \\
\hline $1998-2006$ & 4288 & 2258 & 6362 & 36 & 42 & 38 \\
\hline $2007-2015$ & 2038 & 586 & 2623 & 29 & 28 & 29 \\
\hline Total & 5591 & 3618 & 9258 & 39 & 46 & 42 \\
\hline
\end{tabular}

PYLL: potential years of life lost $=\Sigma(70-$ age at the time of death). AYLL: average years of life lost $=$ PYLL / number of death.

\subsection{Effect $s$ analysis for the safety measures}

The proportion of smoking cause (PSC), mortality per $10^{2}$ burned houses (MBH), and fire casualty rate (FCR) were $16.53 \%, 21.27$, and $39.29 \%$ during 1989-1997, which declined significantly to $8.98 \%, 8.79$, and $25.44 \%$ during $2007-2015(54.33 \%, 40.51 \%$, and $64.75 \% ; \mathrm{p}<0.05)$. The most significant effect of fire safety measures was evasion training that reflected the indicator of $\mathrm{MBH}$ (Table3).
Table 3: Estimated Major Cause of Fire Deaths and Casualty in the Buildings, Taiwan, 1971-20165

\begin{tabular}{llll}
\hline Year & PSC $(\%)$ & MBH (persons/ $10^{2}$ fires) & FCR $(\%)$ \\
\hline $1971-1979$ & 11.63 & 7.02 & 34.05 \\
$1980-1988$ & 11.75 & 11.61 & 44.84 \\
$1989-1997$ & 16.53 & 21.70 & 39.29 \\
$1998-2006$ & 12.40 & 8.52 & 23.01 \\
$2007-2015$ & 8.98 & 8.79 & 25.44 \\
Total & 12.26 & 12.43 & 33.33 \\
\hline
\end{tabular}

PSC: proportion of smoking cause. MBH: mortality per $10^{2}$ burned houses. FCR: fire casualty rate.

\subsection{Initiatives analysis}

The rates of unqualified recheck (RUR) was $46.08 \%$ during 1995 1997 that declined significantly to $9.46 \%$ during $2007-2015$, 
$(20.53 \%, \mathrm{p}<0.05)$. The persons attendance at every fire accident $(\mathrm{PAF})$, engines attendance (EAF) at every fire incidence, and number of saving at every fire (SAV) were $21.19,5.68$, and 0.15 during $1995-1997$, which increased significantly to 215.74 persons / fire, 73.14 engines / fire, 0.32 person / fire during 2007 2015 (10.18 folds, 12.88 folds, 2.13 folds, $\mathrm{p}<0.05$ ) (Table 4).

Table 4: Fire Inspection, Services, and Call Frequency in Taiwan, 19952015

\begin{tabular}{lllll}
\hline Year & RUR $(\%)$ & PAF & EAF & SAV \\
\hline $1995-1997$ & 46.08 & 21.19 & 5.68 & 0.15 \\
$1998-2006$ & 12.83 & 40.85 & 10.85 & 0.13 \\
$2007-2015$ & 9.46 & 215.74 & 73.14 & 0.32 \\
Total & 16.14 & 122.66 & 40.08 & 0.22 \\
\hline
\end{tabular}

RUR: rates of unqualified recheck. PAF: persons attendance at every fire accident.

EAF: engines attendance at every fire accident. SAV: number of saving at every fire.

The RUR was correlated with FCR $(r=0.50, p<0.05)$. The PAF was correlated with SAV, and CDR respectively ( $\mathrm{r}=073$, and $0.80, \mathrm{p}<0.05)$, The EAF was correlated with SAV, and CDR respectively $(r=073$, and -0.80 , all $\mathrm{p}<0.05)$. These results indicated that the initiatives of fire rescue, and emergency medical services could save the life and decrease the fire death effectively (Table5).

\section{Discussion}

In the past 27 years (1974-2000), the crude death rate due to unintentional injuries overall dropped by $8.56 \%$, however for fire it increased by $28.05 \%$ (Ministry of Health and Welfare, 1974$2000 \mathrm{~b}$ ). Therefore, the large number of losses and casualties due to fires in Taiwan continue to be a major challenge to the fire safety providers and society. Otherwise, there were downward trends of fires, burned houses, and number of casualty after 2000.The CDRs of under 15 years age group, in 15-64 years age group, and over 64 years age group were 1.58 per $10^{5}, 1.72$ per $10^{5}$, and 4.08 per $10^{5}$ during $1989-1997$ and declined to 0.30 per $10^{5}, 0.34$ per $10^{5}$, and 1.41 per $10^{5}$ during $2007-2015$ (18.99\%, 19.77\%, and $34.56 \% ; \mathrm{p}<0.05)$. These signs explained that fire death rates were fallen as a result of caring out the ROC Child Welfare Law of Children supervision and protection and the provision of the National Fire Agency (Children's Bureau Ministry of Interior, 2003; National Fire Agency Ministry of Interior, 2015).

Table 5: The Spearman's Rank Correlation Coefficient for Relationships between Fire Safety Initiatives with Respect to Life-Threatening Hazards from Fire, 1995-2015

\begin{tabular}{lllll}
\hline parameter & SAV & CDR & MBH & FCR \\
\hline RUR & 0.00 & 0.38 & 0.28 & $0.50^{*}$ \\
PAF & $0.73^{*}$ & $-0.80^{*}$ & -0.02 & 0.11 \\
EAF & 0.73 & $-0.80^{*}$ & -0.00 & 0.15 \\
\hline
\end{tabular}

$*$ : the correlation coefficients were significant, $\mathrm{p}<0.05$

During 1971-1980, the average death rate $\left(C D R=1.01\right.$ per $10^{5}$ persons) in Taiwan was lower than the average CDR (4.60 per $10^{5}$ persons; $p$ < 0.05) in U.S.A.(Clark et al. 2000). During 1981-1900, the average death rate $\left(\mathrm{CDR}=1.65\right.$ per $10^{5}$ persons $)$ in Taiwan was lower than in U.S.A $\left(4.55\right.$ per $10^{5}$ persons; $\left.p<0.05\right)$, and in New Zealand (2.1 per $10^{5}$ persons; $\left.\mathrm{p}<0.05\right)$ (Clark et al. 2000; Waller et al. 1998). During 1991-2000, the average death rate $(C D R=1.61$ per $10^{5}$ persons) in Taiwan was similar to the average CDR $(1.65$ per $10^{5}$ persons; $\left.p>0.05\right)$ in U.S.A. but lower than the average CDR (4.60 per $10^{5}$ persons; $p<0.05$ ) in Iran (Clark et al.2000; Panjeshahin et al. 200). During 1996-2000, the average death rate $\left(\mathrm{CDR}=1.25\right.$ per $10^{5}$ persons) in Taiwan was similar to the average CDR (1.22 per $10^{5}$ persons; $\left.p>0.05\right)$ in Wisconsin U.S.A. (Stockhausen \& Katcher 2001). For such incidences in Taiwan past 30 years were there in contrast to reports from developing countries, but conform to reports from developed countries.
Males appeared to be with a higher mortality than females for both adult age groups $(\mathrm{p}<0.05)$. Most studies have also reported a preponderance of burnt males (Roger 1980, Bang \& Mosbah 1988, Tejerina et al.1992, Reig et al. 1994, Elisdottir et al.1995, Barret et al. 1999). However, other studies have reported that female were the victims of fires more frequently than males in developing countries (Liu et al.1998, Mzezewa et al.1999). The declined rates were smaller in over 64 year age group than in under 15 years age group, and in $15-64$ years age group respectively. It suggested that the elders are more vulnerable to fire fatality because they lack the capacity to take "mature independent escape action" (Marshall et al.1998, Mcgwin et al.1999). Our results agreed with these studies expectantly.

The PYLL, AYLL, and CDR of fire deaths were decreased about $85 \%, 36 \%$, and $82 \%[(17455-2623) * 100 / 17455,(45-29) * 100 / 45$, and (1.85-0.33)*100/1.85] from during 1989-1997 to during 20072015. The value of the PYLL and AYLL were heavily influenced by age structure among different population, and were presented indexes that focuses more on the social, economic, and administration consequences of mortality rates (Hartunian et al.1980, Chuang et al.1993, Lai \& Hardy 1999). The studies found that PYLL is the most efficient evaluation for the fire safety measures. The PSC, MBH, and FCR of the fires were decreased about $46 \%$, $59 \%$, and $35 \%[(16.53-8.98) * 100 / 16.53,(21.70-8.79) * 100 / 21.70$, and (39.29-25.04)*100/39.29] from during 1989-1997 to during 2007-2015. The three indicators are all effective for explaining the safety measures. The most significant effect of fire safety measures was evasion training that adopted the indicator of $\mathrm{MBH}$. With comparing the changes of indicators between during 19711979 and 1989- 1997, and between during 1998-2006 and 20072015, we found that the change of indicators were more consistently in the later. A law of Children supervision and a provision of fire fighting both addressed the issue of how to decrease risks of deaths.

The fire safety efforts such as RUR, PAF, and EAF were confirmed to the effectiveness of fire safety measures that could decrease the death and .casualty in our studies, expectantly. During 1995-2013, the proportions of fir safety appropriations (about $\$$ 20.78 millions dollars) are $8.74 \%$ with fire prevention, $75.94 \%$ with fire rescue and emergency medical services, and $15.32 \%$ with fire investigations in 2002 (National Fire Agency Ministry of Interior, 2015). These signs implied that the process of the fire safety measures is parallel, the appropriation of fire prevention is light, but is effective. Therefore, if we weight the proportion of fire prevention appropriations, we will decrease the overall fire safety appropriations; as well as, if we emphasize the fire prevention initiatives, we would decrease the fire mortality and casualty.

\section{Conclusion}

The mortality rate was higher in male and in the elders. The PYLL implied the most efficient evaluation for the fire safety measures. Fire mortality and casualty could be prevented by fire prevention, fire rescue and emergency medical measures effectively. The most significant effect of fire safety measures was evasion training that adopted the indicator of $\mathrm{MBH}$.

\section{References}

[1] Bang RL, \& Mosbah KM (1988). Epidemiology of burns in Kuwait. Burns Incl Therm Injury 14, 194-200. http://dx.doi.org/10.1016/0305-4179(88)90038-1.

[2] Barillo DJ. \& Goode R (1996). Fire fatality study: demographics of fire victims. Burns 22, 85-88. http://dx.doi.org/10.1016/03054179(95)00095-X.

[3] Barret JP, Gomez P, Solano I, Gonzalez-Dorrego M, \& Crisol F J (1999). Epidemiology and mortality of adult burns in Catalonia. Burns 25, 325-329. http://dx.doi.org/10.1016/S03054179(98)00190-9.

[4] Children's Bureau Ministry of Interior, 2003. ROC Child Welfare Law. http://www.cbi.gov.tw/all-law.php?id=16\& t_type=dis 
[5] Chuang CH, Liu YH, \& Wang JD (1993). Cumulative mortality rate and years of potential life loss due to fire in Taiwan during 1971-1990. Journal of National Public Health Association Republic of China12, 380-391

[6] Clark DE, Dainiak CN, \& Reeder S (2000). Decreasing incidence of burn injury in a rural state. Injury Prevention 6, 259-262. http://dx.doi.org/10.1136/ip.6.4.259-a.

[7] Department of Statistics Ministry of Health and Welfare, 19712015b. Health and Vital Statistics. Department of Statistics. Ministry of Health and Welfare, Taiwan.

[8] Department of Statistics Ministry of Interior, 2015. Abridged Life Tables of Taiwan-Fuchien Area. Department of Statisics Ministry of Interior, Taiwan.

[9] Etter IB (1987). Costs of injury. Public Health Reports 102, 634 637.

[10] Elisdottir R, Ludvigsson P, Einarsson O, Thorgrimsson S, \& Haraldsson A (1995). Paediatric burns in Iceland. Hospital admission 1982-1995, a populations based study. Burns 25, 149-151

[11] Hartunian NS, Smart CN, \& Thompson MS (1980). The incidence and economic costs of cancer, motor vehicle injuries, coronary heart disease, and stroke: a comparative analysis. AJPH 70, 12491260. http://dx.doi.org/10.2105/AJPH.70.12.1249.

[12] Lai D \& Hardy RJ (1999). Potential gains in life expectancy or years of potential life lost: Impact of competing risks of death. International Journal of Epidemiology 28, 894-898. http://dx.doi.org/10.1093/ije/28.5.894.

[13] Liu EH, Khatri B, Shakya YM, \& Richard BM (1998). A 3-year prospective audit of burns patients treated at the Western Regional Hospital of Nepal. Burn 24, 129-133. http://dx.doi.org/10.1016/S0305-4179(97)00103-4.

[14] Marshall SW, Runyan CW, Bangdiwala SI, Linzer M A, Sacks JJ, $\&$ Butts JD (1998). Fatal residential fires: who dies and who survives? JAMA $279, \quad 1633-1637$. http://dx.doi.org/10.1001/jama.279.20.1633.

[15] Mcgwin G J, Chapman V, Curtis J, \& Rousculp M (1999). Fire fatalities in older people.J Am Geriatr Soc 47, 1307-1311. http://dx.doi.org/10.1111/j.1532-5415.1999.tb07430.x.

[16] Miettinen OS (1972). Standardization of risk ratios. Am J Epidemiol 96, 168-172.

[17] Mzezewa S, Jonsson K, Aber M, \& Salemark K (1999). Prospective study on the epidemiology of burns in patients admitted to the $\mathrm{Ha}-$ rare burn units. Burns 24, 134-138. http://dx.doi.org/10.1016/s0305-4179(99)00041-8.

[18] National Fire Agency Ministy of the Interior, 2015. Organizational History. http://www.nfa.gov.tw/main/Index.aspx?ID=2

[19] National Fire Fighting Administration, 2002. The organization and appropriation of firefighting. In White BooK of Fire Fighting, Taipei, Taiwan,pp. 7-14.

[20] Panjeshahin MR, Lari AR, Talei AR, Shamsnia J, \& Alaghehbandan R (2001). Epidemiology and mortality of burns in the South West of Iran. Burn 27, 219-226. http://dx.doi.org/10.1016/S03054179(00)00106-6.

[21] Reig A, Tejerina C, Baena P, \& Mirabet V (1994). Massive burns: a study of epidemiology and mortality. Burns20, 51-54. http://dx.doi.org/10.1016/0305-4179(94)90106-6.

[22] Roger MS (1980). Deaths due to accidents in Taiwan: A possible indicator of deelopment. Soc. Sci. \& Med 14, 361-367.

[23] Stockhausen AL, Katcher ML (2001). Burn injury from products in the home: prevention and counseling. WMJ100, 39-44.

[24] Tejerina C, Reig A, Codina J, Safont J, Baena P, \& Mirabet V.(1992). An epidemiological study of burn patients hospitalized in Valencia, Spain during 1989.Burns 18, 15-18. http://dx.doi.org/10.1016/0305-4179(92)90112-8.

[25] Waller AE, Marshall SW, \& Langley JD (1998). Adult thermal injuries in New- Zealand resulting in death and hospitalization. Burns 24, 245-251. http://dx.doi.org/10.1016/S0305-4179(98)00018-7. 